\title{
A review of metro construction in China: Organization, market, cost, safety and schedule
}

(C) The Author(s) 2017. Published by Higher Education Press. This is an open access article under the CC BY license (http:// creativecommons.org/licenses/by/4.0)

\begin{abstract}
China is now in an era of large-scale metro construction. This paper reviews the nature of Chinese metro engineering with a specific focus on its organization and market mode, cost structure, safety control and schedule management. Then, an examination on recent research in metro engineering of the National Natural Science Foundation of China (NSFC) is also conducted, which indicates that information and automation based technologies are increasingly used in practice.
\end{abstract}

Keywords metro engineering, construction status, construction challenges, NSFC

\section{Introduction}

The well-esteemed Academician Mengshu Wang, member of the Chinese Academy of Engineering, highlighted that China had the largest, most complex and fastest growing tunnel and underground engineering in the world (Wang, 2003). The 50-year development history of Chinese metro engineering can be divided into two distinct periods (Chen, 2014):

(1) Initial development stage (1965-1999) - Beijing Metro Line 1 is a typical metro project at this stage. As the first metro line in China, it was planned in the 1950s, constructed from 1965, and finally completed in October, 1969. In the $1980 \mathrm{~s}$, a number of metro lines were respectively planned and constructed, such as Shanghai Metro Line $1(21 \mathrm{~km})$ and Guangzhou Metro Line 1 $(18.5 \mathrm{~km})$ (Chen, 2014). However, in the 1990s, metro construction suffered from an administrative obstacle. The

Received March 3, 2017; accepted March 6, 2017

Lieyun DING ( $₫)$, Jie XU

Hubei Engineering Research Center for Virtual, Safe and Automated Construction, Wuhan 430074, China; Department of Construction Management, School of Civil Engineering and Mechanics, Huazhong University of Science and Technology, Wuhan 430074, China

E-mail: dly@hust.edu.cn general office of the State Council issued Document No. 60, terminating all the metro projects except for the Shanghai Metro Line 2 project. By the end of 1997, metro engineering projects re-commenced when the State Planning Commission proposed several projects such as Shenzhen Metro Line 1 (19.5 km) (Gu, 2011; Jin et al., 2014).

(2) Booming stage (post 1999)-Entering the 21st century, in consideration of significantly growing demand of people's public transportation, the Chinese government approved the metro construction in cities such as Shenzhen, Shanghai, Guangzhou, Chongqing, and Wuhan. This initiative has ignited a new era of metro development in these cities (Jin et al., 2008; Department of Transportation, 2012).

The Chinese metro is now boosting its development, reaching a historically high level in terms of the construction speed, scale and investment. During the period of the 12th Five-Year National Development Plan, there were total $2019 \mathrm{~km}$ urban metro lines entering operation, with an investment of 1.23 trillion $\mathrm{CNY}$ and having fulfilled a traffic volume of 52.8 billion persontimes. By the end of 2015, 111 metro lines in 25 cities totaling $3295 \mathrm{~km}$ had entered commercial service; the total investment of approved metro projects, with a construction scale of $4705 \mathrm{~km}$, are approximately 2.63 trillion CNY (China Urban Rail Transit Association, 2016) (see Appendix).

By 2020, according to the National Planning, it is expected that a large urban metro network is to be built up, with a total length of over $6600 \mathrm{~km}$, including nearly 3000 $\mathrm{km}$ new metro lines costing a total investment of around 2 trillion CNY (China Urban Rail Transit Association, 2016). Furthermore, the number of metro lines is anticipated to reach 300 , a historical peak by 2050 . At that time, the total mileage of metro lines is expected to be $11,700 \mathrm{~km}$ in the mainland of China, which is almost ten times of the current scale (Ministry of Commerce of the People's Republic of China, 2015). 
In such a context, the paper, through an extensive review of the normative literature, identifies four main challenges associated with metro construction practice: (1) Organization and market mode, (2) cost structure, (3) safety control and (4) schedule management. The research programs on metro engineering funded by the National Natural Science Foundation of China (NSFC) in recent years is also examined.

\section{Organization and market mode of metro construction in China}

There are differences in the urbanization level among different regions in China due to the difference in the geological conditions and the historical and cultural environment. Consequently, the management system has become the focus of academic and business circles (Sureeyatanapas et al., 2014). In this case, Chinese metro construction closely matches with the specific situation in China. Noticeably, different organizations and market modes are formed with a reform trend of diversity and marketization (Zhang, 2009). The investment and financing mode has also undergone different phases in order to constantly adapt to the development of the metro market.

\subsection{Organization and market mode}

The organization and market mode of Chinese metro construction runs in a different way from that of developed countries, which features high economic power and welfare, low speed of construction and long-term government subsidy. The four key features of Chinese metro construction are:

(1) Construction is undertaken and accomplished by a local contractor. Generally, this local contractor has some relationship with the local government, or rather, the staff of some departments directly come from the local government.

(2) The organization mode of metro enterprises varies between cities and is dependent on the local economic and social development levels. There are mainly two types of organization mode in China. One is that a corporation undertakes the entire process of a metro project, including the investment and financing, construction and operation management, such as the Guangzhou Metro; while the other is that several professional companies are involved in one metro project, respectively responsible for different functions like investment, construction and operation, such as the Beijing Metro, the Shanghai Metro and the Shenzhen Metro. See Table 1 for more details.

(3) A joint development model of metro, real estates and other estates is adopted in some cities to ensure adequate investment and financing to support the metro construction. Two examples are presented. The Guangzhou Metro Corporation performs the construction work combining with real estate and property development along the metro line. In the case of the Wuhan Metro, the Wuhan Metro Corporation builds a town called Metro Town in the vicinity area along metro lines while promoting metro

Table 1 Chinese metro corporation organization modes (Liu, 2015)

\begin{tabular}{|c|c|c|c|}
\hline Organization type & Management framework & Function assignment & Case \\
\hline One metro corporation & $\begin{array}{l}\text { One metro headquarter including eight } \\
\text { functional departments, two offices and } \\
\text { one technical committee. }\end{array}$ & $\begin{array}{l}\text { - Metro headquarter: Responsible for the construction and } \\
\text { operation of Guangzhou Rapid Rail Transit System as well } \\
\text { as the development of real estate along the lines; } \\
\text { - Guangzhou Municipal Planning Commission Metro } \\
\text { Finance Office: Responsible for financing. }\end{array}$ & Guangzhou Metro \\
\hline
\end{tabular}

Several different professional companies
One metro headquarter with six functional departments and several subsidiary companies responsible for investment, construction etc.

Four professional companies responsible for financing, construction, operation and supervision respectively.

One enterprise group including the construction company and operating company etc.
- Metro Investment Company: As a real owner, responsible for financing;

- Metro Construction Company: As an executive owner, responsible for construction.

- Shen Tong Company: As a real owner, responsible for investment and financing;

- Metro Construction Company: Responsible for metro construction;

- Metro Operation Company: Responsible for metro operation;

- Rail Transit Administration: Responsible for metro industrial supervision.

- Urban Facility Investment Company: Responsible for planning and investment;

- Mero Construction Company: Responsible for construction management;

- Metro Operation Company: Responsible for operation;

- State owned Assets Management Committee: Responsible for supervision of the three companies.
Tianjin, Nanjing, and Shenzhen Metro

Shanghai Metro

Beijing Metro 
construction in this city.

(4) As China is a socialist state, there is strong administrative intervention over primary industries of national economy and the people's livelihood, including the metro industry. During the era of planned economy, investment in the Beijing Metro was entirely from the local government. The Guangzhou Metro runs an integration mode of construction, operation and resource development learning from the experience of Hong Kong Metro, with an accrediting system implemented. However, the Shanghai Metro provides a competitive market for a number of construction units and operating agencies (Song, 2001).

For metro construction in China, the administrative department, namely Traffic Management Bureau or Metro Engineering Bureau performs functions of planning, investment, construction and supervision; while the metro companies are mainly responsible for operation and management of metro lines, and advisory bodies are encouraged to provide technical and consulting services. This indicates a trend of reform and division of the metro market. Overall, the public-private-partnerships (PPP) mode is necessary for it can stimulate the development of macro metro industry and the whole society. A win-winwin situation among the government, metro and stakeholders can be expected through the effective integration of management and technical resources (Yang, 2014).

\subsection{Investment and financing methods}

With the development of construction management, the investment and financing system is under improvement (Sun, 2014). Previously, Chinese metro construction is characterized by single investment entity, limited financing channel, fund shortage and low profitability, which seriously restricted its development (Song and Chen, 2015). The investment in metro construction had been influenced by the planned economy, with all the investment coming from the government. A typical example is Beijing Metro Line 1 in 1965 when the central government bore all the burden (Chen, 2005).

With the increasing scale of metro construction, the huge capital demands created another kind of investment and financing mode; that was the government-led debt financing mode. In this context, the government partly invests with a dependence on their credits, implementing financing by bank loans and bonds issued. For instance, the investment of the Shanghai Metro Line 1 was 680 million USD with a foreign capital of 300 million (Xia, 2000).

The financing modes for construction project are now required to be closely connected with the development of society (Zhu, 2014). New investment methods are also widely applied in China, including BOT (building-operatetransfer) and BT (building-transfer) (He, 2004). The typical characteristic of the new methods is that third parties (enterprises), with their professional technologies and capital management experience, are introduced in the metro construction process, which not only greatly reduces the burden on the governments, but also enhances the efficiency of capital use, the professional management of projects and the market operation of metro lines (Song and Chen, 2015).

However, for BT and BOT modes, enterprises and other social institutions are temporary. The operation is to be given back to the government for professional life cycle management of the metro project. With a trend toward marketization and diversification of investment and financing, PPPs are becoming a viable alternative (Chen, 2006). This mode combines the governments, enterprises, foreign banks and other subjects such as the project owner. By introducing the social capital, the government's financial pressure is reduced and the operation efficiency is also improved. The intervention of a third party goes through the whole process of metro construction and operation catering to the market economy reform path of Chinese government. Table 2 shows the evolvement of Chinese metro investment and financing modes.

\section{Cost structure of Chinese metro construction}

\subsection{Cost structure}

The high cost of metro construction has become a

Table 2 Evolvement of Chinese metro investment and financing modes

\begin{tabular}{lcc}
\hline Investment and financing mode & Period & Case \\
\hline Government investment & Early stage & Beijing Metro Lines 1 and 2 (Chen, 2005) \\
Government-led debt financing & Early and middle stages & $\begin{array}{c}\text { Shanghi Metro Line 1 (Xia, 2000), } \\
\text { Project financing }\end{array}$ \\
BT & Middle and late stages & Beijing Metro Olympic Branch Line (Zhu et al., 2014a), \\
BOT & Middle and late stages & Shenzhen Metro Line 5 (Wei et al., 2012) \\
& & Shenzhen Metro Line 4 (Zhang et al., 2006), \\
Nanjing Metro Line 2 (Yao et al., 2013) \\
Diversified financing (PPP) & Currently & Beijing Metro Line 4 (Wang, 2005), \\
& & Nanjing Metro Line 1 (Zhang, 2014b)
\end{tabular}


significant concern of the local governments. According to Mr. Liyong Wang's Technical and Economic Indexes of Urban Rail Transit Project (Wang, 2016), the cost structure of metro construction includes the following contents: Civil engineering costs of metro station, tunnel, track, vehicle base, transportation, signal, power supply system and electrical and mechanical equipment, installation costs, other construction costs, reserve costs, vehicle purchase costs, loan interest and working capital flows. These costs can be classified into four parts: (1) Project cost, (2) construction cost, (3) preparatory fee, and (4) special cost.

At present, the B-type six-group model which has six Btype coaches in a vehicle group is most commonly used for Chinese metro construction. Among the 119 metro lines which will be built in the next five years, there are 60 lines of B-6. In a B-6 group of metro project, the first part of cost accounts for about $60 \%$ of the total cost; the second part of cost is about $20 \%$; the third part is about $4 \%$; and the fourth part represents $16 \%$. The project cost accounts for the largest proportion of the total cost. Specifically, the total cost of B-6 group can be divided into several parts of station, regional tunnel, power supply system (excluding power lighting), vehicle base, track and other electromechanical system, pre-project fee, other expenses, reserve fee, vehicle purchase fee and loan interest which are shown in Fig. 1.

(1) Station: Cost of building and decorating metro stations is about $20.5 \%$ of the total metro project cost. Another included costs are related to power lighting, ventilation and air conditioning, water supply and drainage, fire and security, security and access control, Fire Alarm System (FAS), Building Automation System (BAS), automatic sales, escalators and station doors, air defense and other electromechanical systems, accounting for about $8 \%$ of the total metro project cost. Therefore, the total cost of a station approximately represents $28.5 \%$, about $1 / 3$ of the total metro project cost, which mainly depends on the station size, station spacing, layouts, construction methods and other factors. Larger station size, smaller station spacing, greater proportion of underground parts and worse geological situation all contribute to a higher cost of a station.

(2) Regional tunnel: Cost of the tunnel projects is approximately $15 \%$ of the total metro project cost, which is mainly affected by the tunnel arrangement, construction method, and foundation and building reinforcement factors. Longer underground section contributes to a higher cost of regional tunnel.

(3) Power supply system: Cost of the power supply system (excluding power lighting) accounts for about $4.5 \%$ of the total metro project cost. The main factors include capacity of the main transformer substation, length of the $110 \mathrm{kV}$ line and corresponding laying method, regenerative brake energy absorption device, traction network type (catenary/contact rail), etc. A larger number of main substations, longer $110 \mathrm{kV}$ line, and a greater proportion of underground laying, all contribute to a higher cost of the power supply system.

(4) Vehicle base: Cost of the vehicle base is about $4.5 \%$ of the total metro project cost, which is mainly influenced by factors such as the size of base plant, the geological situation and the process equipment. Larger size of base plant, poorer geological conditions and a larger amount of equipment, all contribute to a higher cost of the vehicle base.

(5) Pre-project cost: Pre-project cost is about $10 \%$ of the total metro project cost. It is mainly affected by the

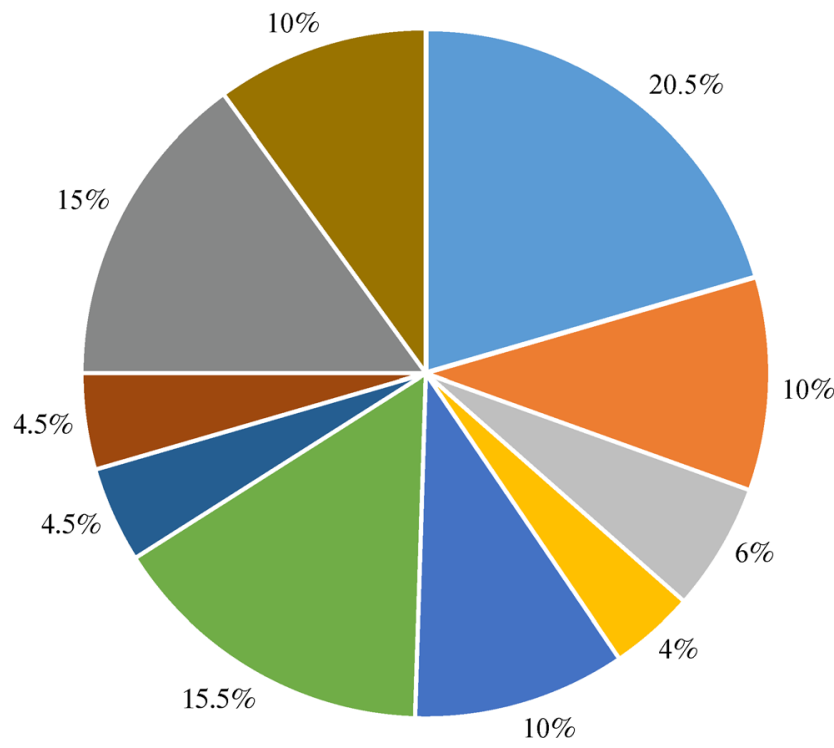

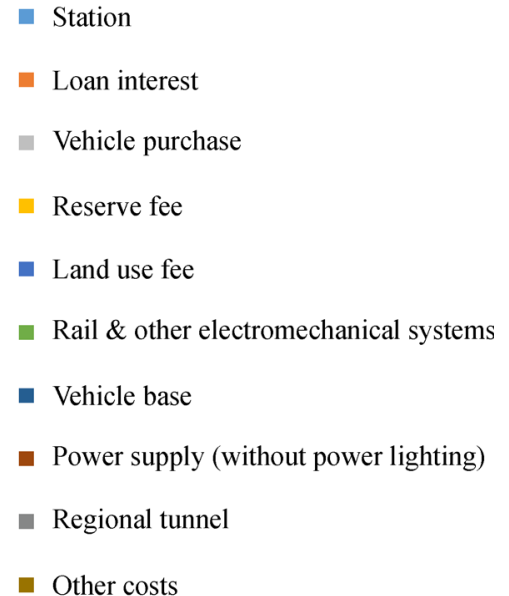

Fig. 1 Proportions of different costs of the B-6 group metro engineering 
demolition area and the compensation standard, and it is also an important factor affecting the total metro project cost. A larger demolition area and higher compensation standard both contribute to a higher pre-project cost.

(6) Vehicle purchase fee: The vehicle purchase fee is about $6 \%$ of the total metro project cost. It is mainly influenced by the number of initial vehicles, vehicle type and the speed of vehicles. A larger number of vehicles in the initial period, an A-type vehicle and higher speed, all contribute to a higher vehicle purchase cost.

(7) Loan interest: The proportion of loan cost during the construction is about $10 \%$ of the total metro project cost, which is mainly affected by the loan interest rate, duration and loan ratio. A higher loan interest rate, longer duration and higher proportion of loans, all contribute to a higher cost of construction loans.

\subsection{Cost difference analysis}

With the metro engineering cost remaining in China, it can significantly vary among lines and cities. Reasons for these differences include:

(1) With the increasing demands for urban public transport during the urbanization process, standards and specifications of metro engineering are gradually improved, resulting in the fact that the cost of a metro project has been increasing gradually during the past decades. In Beijing, for example, the cost of metro construction per kilometer has risen sharply compared with that in 1984. An average cost of 150 million CNY per kilometer of Metro Line 2 (1984) went up to an average cost of 500 million CNY per kilometer in 2007 when Metro Line 5 was put into operation. Furthermore, the average cost per kilometer of Lines 3 and 12 under construction has exceeded 1.1 billion CNY, which is more than 7 times of that in 1984 (Beijing Morning Post, 2016).

(2) Due to the different economic and social development levels, there is a municipal grading of first-tier, second-tier and third-tier cities. First-tier cities apply far higher metro construction technical specifications than the second-tier and third-tier cities, while the second-tier and third-tier cities roughly use the same technical specifications, which leads to similar performance of the metro lines. According to the city metro construction plan during the period of the 13th Five-Year National Development Plan approved by the National Development and Reform Commission, the average cost per kilometer of metro lines in first-tier cities is 804 million CNY, while that of secondtier cities such as Wuhan and Nanjing, which are undergoing rapid development of public transportation, is 663 million $\mathrm{CNY}$ and that of third-tier cities such as Guiyang is 662 million CNY.

(3) From the aspect of vehicles, metro engineering cost rises with the upgrade of selected vehicles. For example, the A-6 group and A-8 group, cost 857 million and 754 million CNY per kilometer, respectively. The per kilometer costs of B-4 group, B-6 group and B-8 group are 712 million, 682 million and 531 million CNY, respectively. The A-type vehicle is generally used in first-tier and second-tier cities.

(4) Costs of metro engineering in some special cities are also affected by such factors like the preservation of cultural relics, special planning, urban planning, etc. For instance, Luoyang Metro Line 2 costs up to 935 million CNY per kilometer due to the preservation of cultural relics in sensitive areas(Wang, 2012b); Wuhu Metro Lines 1 and 2 adopt the straddle type monorail train with the low costs of 334 million and 363 million CNY per kilometer (Zhang et al., 2013); Multiple Units trains are likely to be used for long distance metro lines such as Beijing Pinggu Metro Line, of which the cost is only 299 million CNY per kilometer (Beijing Morning Post, 2016).

\section{Safety control of Chinese metro construction}

\subsection{Challenges of safety control}

The technical standards of safety control play a key role in guaranteeing the healthy development of metro engineering. The existing safety control standards of metro engineering can be divided into the following three categories: (1) Various types of factors such as technology, economics, function and other aspects of technical standards; (2) metro engineering safety control standards; and (3) worker behavior regulations. However, there are apparent problems in the existing safety standards.

Requirements of metro engineering safety technologies are scattered in various professional and technical standards, such as metro engineering design specifications, metro engineering construction standards which contain safety content lacking of consistency and integration. This sets up barriers for the governments and construction enterprises to carry out effective safety management. Currently, metro construction refers to a large number of standards of the railway systems and general engineering construction standards, as well as international standards in some respects. Although China has developed standards to guide the metro construction, these standards mostly concentrate on the technical aspects such as design and construction, with limited coverage on environmental protection. Safety-related standards are particularly deficient. The overall safety standard system of metro engineering is imminent to be improved (Liu, 2011).

With the problems of existing safety standards, safety accidents often occur in construction projects. According to the statistics of the Ministry of Housing and Urban (Ministry of Housing and Urban Rural Development of People's Republic of China, 2017), nearly 80 accidents took place from 2011 to 2016 during metro construction, including high falling and other types of accidents. Among 
them, the high falling, collapse and object strike were the most frequent types of accidents, accounting for up to $66 \%$ of the total accidents; vehicle injury, electric shock and lifting injury respectively took an identical proportion of about $6 \%$ which was slightly lower than that of mechanical injury, 7\%, as seen in Fig. 2a. From a geographical point of view, these accidents cover all cities throughout the country having metro construction projects from 2011 to 2016. Wuhan, Beijing and Shenzhen ranked the top three in terms of the number of accidents and Shanghai, Ningbo, Suzhou, Nanning and other cities also had several safety accidents as seen in Fig. 2 b.

The occurrences of these safety accidents are often related to the complex geological conditions of metro engineering, the construction environment and the poor construction site safety monitoring and other human factors. For this, experts, engineers and technicians put forward a variety of technical measures and research involving risk reduction and safety control for metro construction.

\subsection{Technical measures and research for risk reduction}

Risk reduction aims to deal with different geological conditions and complex construction environment, which concerns the external relationship between surrounding

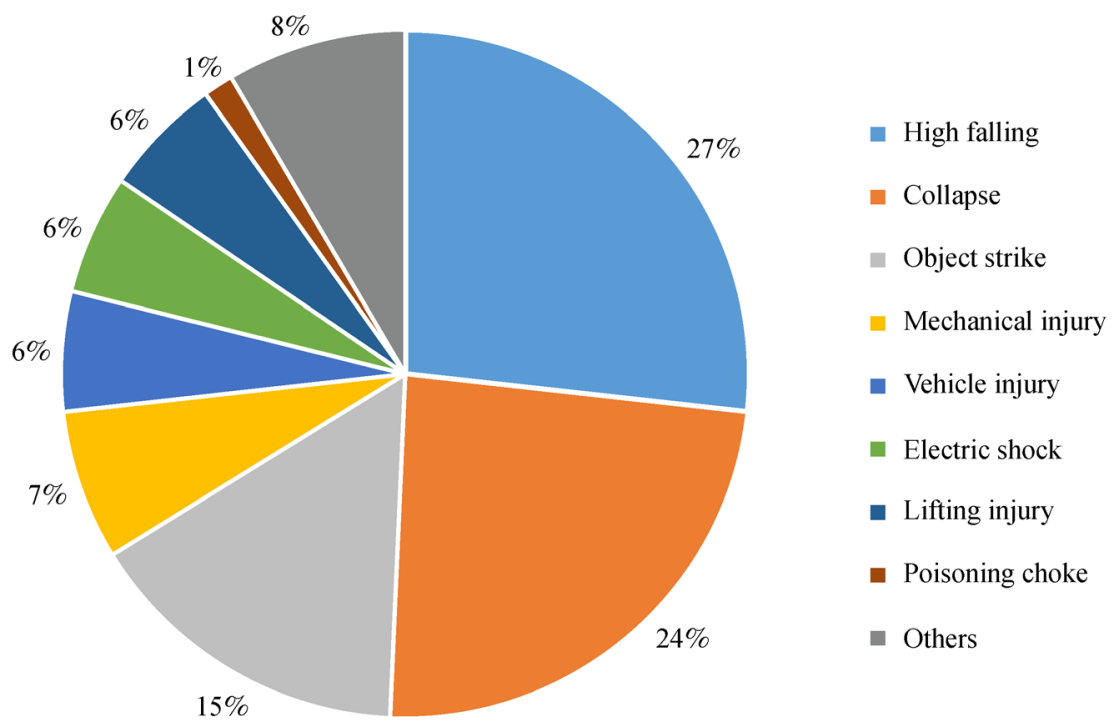

(a)

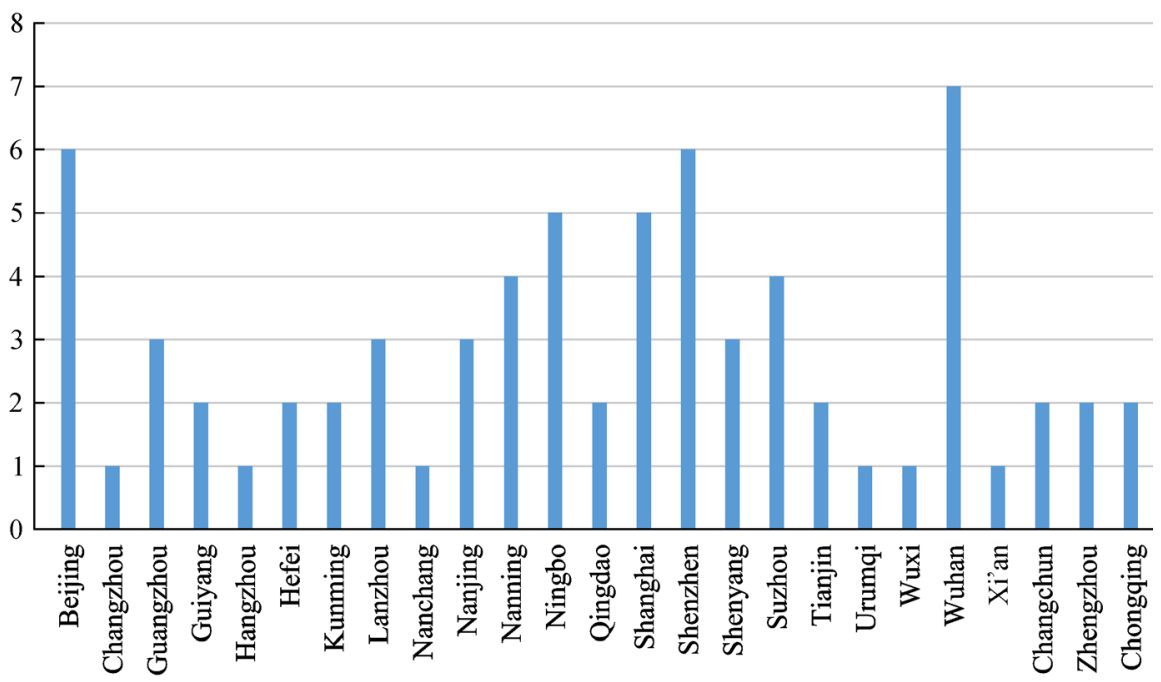

(b)

Fig. 2 Statistical analysis of safety accidents in domestic metro construction in recent five years (a) Division by accident types; (b) division by regions 
environmental conditions and construction safety. This is the basic premise of metro construction safety control.

\subsubsection{Geological conditions processing}

The tectonic structure, landform, hydrology, meteorology, and other basic geological conditions vary from region to region in China, which results in diversified safety risks of the metro construction projects. According to the differences of geotechnical characteristics, the geological conditions in each region can be divided into five types: Soft soil area, alluvial soil area, loess area, expansive soil area and bedrock or geological unit complex area. It is necessary to take different safety measures in different geological conditions to ensure project safety.

(1) Soft soil area: Typical areas are Shanghai and Tianjin. Stratigraphy in soft soil areas is mainly marine sediments, river or lake siltation and muddy soil. The main engineering geological problems are soft soil strength, deformation, seismic subsidence and un-consolidation. For this soil condition, EPB (earth pressure balanced) shield machine is suitable for the tunneling to ensure the minimum disturbance to the soil (Wang, 2014), and special attention shall be paid to structural waterproofing during the construction.

(2) Blunt diluvial soil area: Typical areas include Beijing and Chengdu. The blunt diluvial soil is composed of coarse or fine particles with low-medium to high compressibility, medium shear strength and big permeability difference. The Beijing Yanfang Line is located in the mountains and alluvial fan. The use of rotary digging hole filling pile successfully overcomes the challenges of holing, and shield tool wear during construction of the bridge foundation (Ding et al., 2015).

(3) Loess area: Typical areas include Xi'an and Lanzhou. The main problem of loess is water collapse. Therefore, the tunnel and slope in loess areas are likely to lose stability when encountering groundwater, and ground fissures have a detrimental impact on the metro structure. For metro construction in such areas, Wang (2012b) strengthened the precipitation in the specific area and dealt with the surrounding rocks with poor bearing capacity in ground fissure area, strictly controlling the land subsidence.

(4) Expansive soil area: Typical areas are Nanning and Hefei. Expansive soil is prone to water swelling and water loss, which causes risks in construction. In order to solve such problems as preliminary bracing cracking and convergence in construction of expansive soil tunnel, deformation allowance should be reserved to ensure the quality of preliminary bracing and meet the design requirements of lining thickness after tunnel deformation. Furthermore, bracing should be looped to ensure overall stress to control the tunnel deformation to a considerable extent (Zhai, 2009).
(5) Bedrock or complex geological unit area: Bedrock or complex geological unit areas include Guangzhou and Chongqing. Tunneling in the bedrock area is mainly affected by the integrity and strength of the rock mass. Differences of lithology and rock mass integrity in each city's bedrock result in difference of geological risks. When applying shield construction under method such geological conditions, the engineering staff will promptly check and replace the shield cutter tool and reduce the cutter tool penetration to improve the cutter speed, strictly controlling the amount of excavated earth (Zhang et al., 2008).

\subsubsection{Environmental impact control}

Metro lines are basically located in a complex environment, such as densely populated urban areas surrounded by high-rise buildings and intensive underground pipelines. Some areas still have historical buildings, urban bridges, roads, existing railways and other infrastructures with huge traffic volume. In this case, metro construction is prone to have a significant impact on the surrounding environment, leading to hidden safety risks. Measures are proposed to control the impact, especially on the following four objectives of (a) adjacent buildings, (b) existing infrastructure, (c) historical relics and buildings and (d) underground utilities.

(1) Impact control on adjacent buildings: The vertical (uneven settlement or uplifting) and horizontal (tension and compression) deformation caused by metro construction will result in cracks in adjacent buildings, extrusion deformation and folds or bulging of vertical walls (Wang and Wang, 2002). In order to control the impact on adjacent buildings, engineers use on-site monitoring methods (Sun and Guan, 2012; Ding, 2014) and numerical simulation methods (Yan et al., 2012; Ren et al., 2014). A tunnel model is usually established to analyze the deformation rules to provide guidance and ensure the safety of adjacent buildings.

(2) Impact control on existing infrastructures: Metro tunnels crossing existing bridges, roads, railways and other infrastructures will interfere with the surrounding strata, causing movements or deformations and upper structure damages of bridges, roads, and railway foundations (Wang, 2016). Chen et al. (2015) systematically analyzed the risk of shield under-passing high-speed railway and proposed a set of risk control systems combined with various measures; Tao et al. (2013) used the center cross diagram method combined with top brace control technology in the project of existing metro stations; You et al. (2012) used the pretreatment approach of pile and plate structure along with reinforced segments for the metro tunnel crossing through the Shanghai-Nanjing Railway.

(3) Impact control on historical relics and buildings: 
The metro-under-passing influence on historical buildings and relics cannot be ignored (Yang and Wen, 2010). In the metro construction of Shanghai (Huang et al., 2010), Tianjin (Xu et al., 2013), Xi'an (Yang, 2009), Wuhan (Zhou, 2006) and Hangzhou (Zhao, 2013), particular protection measures were taken on each related historical building in metro construction projects. Zhu et al. (2014b) established a micro-disturbed construction control system in shield driven tunnel construction practice for historic building projects.

(4) Impact control on underground utilities: It is unavoidable for metro lines to encounter the underground pipelines, which might cause uneven underground pipeline settlements, cracks and other damages. In addition, water supply and rain sewage pipelines can bring large amounts of groundwater to the project, leading to the rock instability and resulting in accidents (Huang et al., 2010). In this regard, engineers usually use the theoretical analysis (Wei et al., 2012; Yao et al., 2013), numerical simulation (Zhang and Zhang, 2013; Wang and Cui, 2013) and other means while some experts put forward the safety criteria for buried pipelines ( $\mathrm{Li}, 2014)$, trenchless automated monitoring technology (Zhou et al., 2013), pile-beam exchange and grouting tracking technology (Wang, 2012a), etc.

\subsection{Technical measures and research for safety control}

Safety control focuses on corresponding solutions to poor safety monitoring and site workers' lack in safety awareness and other related issues. This is about the internal relationship between people and activities involved in a project process and construction safety.

\subsubsection{Safety training of worker}

Due to the poor education background of migrant workers, most of them are lack of safety consciousness. According to the statistics of 1731 safety accidents published during the Chinese metro construction from 2008 to 2014, more than $80 \%$ of the accidents were attributable to unsafe behaviors of workers ( $\mathrm{Li}, 2011)$. Therefore, it is necessary to conduct safety training for workers in order to address the problems such as lack of safety knowledge and weak safety awareness. Once their safety awareness and knowledge have been improved and the existing unsafe practices have been corrected, unsafe behaviors of site workers can be avoided to lower the possibility of safety accidents. Currently, many experts and engineers have studied the safety training of workers and proposed a series of methods to verify the effect of training programs, especially for the safety training of personnel in metro construction site.

$\mathrm{Xu}$ and Luo (2014) organized and analyzed the safety operation codes and safety management regulations with knowledge management theories to establish a database describing the process of obtaining, transferring and storing knowledge in detail, and developed a behavior safety training system based on the visual language. Xiao et al. (2015) collected the concerning data and analyzed the application effects in terms of satisfaction of trained construction workers, workers' training test performances and their unsafe behaviors during daily work. The results indicated that the visual language-based safety training system was able to solve the problems confronted in conventional safety training programs. By applying this system to on-site safety training, the safety level and management on metro construction sites can be effectively improved.

Both Ding et al. (2015) and Guo et al. (2015) analyzed the corresponding relationship between types of unsafe behaviors and working positions, relationship between site construction phases and the workers' construction tasks, and relationship between the difficulty coefficients of training contents and the workers' test results. They matched the training contents with workers' characteristics through the similarity algorithms, realizing a personalized pushing mechanism in training contents and improving the safety training effect of metro construction workers.

\subsubsection{Safety monitoring and early warning}

In addition to safety training of workers, there will inevitably be other insecurities in the project sites. Safety monitoring and early warning is of great significance for the metro construction projects. Generally, the early warning management can be divided into three aspects: (1) Risk management, (2) monitoring control management and (3) early warning (Wu et al., 2013).

(1) Risk management: Risk management requires the analysis on the potential risks of a construction plan prior to the commencement of activities on-site, the determination of major risk sources and their special control programs, and the dynamical risk tracking and monitoring during a project progress. Zhang (2014a) used fuzzy logarithm probability and fuzzy logarithmic loss rate to quantitatively analyze the risk events, determining the overall risk level and each risk event of a metro construction project. Ding and Zhou (2012) calculated the possible safety risks and probability of accident occurrence of metro construction by computer-aid automated identification of metro construction drawings.

(2) Monitoring control management: With monitoring programs set before construction, the key content of monitoring management is to determine the monitored objects. In the area of safety monitoring and management, Wang et al. (2013) set a system frame considering the index and the interactional relationship of monitoring objects, using fuzzy analytic hierarchy process (AHP) method. Chen et al. (2013) used a data mining method based on multidimensional association rules to analyze the 
accident data during construction and select key warning signs of the target. Electronic product code (EPC) labels and monitoring billboards were used to identify key warning signs of targets information and radio frequency identification (RFID) technology was used for automated identification and information remote monitoring.

(3) Early warning: Early warning requires the identification of safety risk levels based on warning criteria and response procedures. In the aspect of monitoring early warning, Li et al. (2014) studied the engineering monitoring system, the classification of early warning level, the risk event handling process and the risk event alarm system of Shenzhen Metro Line 5. Li (2011) divided the process of metro construction safety monitoring early warning into five steps: (1) Clear warning, (2) finding the warning sources, (3) analyzing the warning signs, (4) forecasting and eliminating the warning, and (5) constructing the early warning index system of metro construction safety risks.

\section{Schedule management of Chinese metro construction}

5.1 Broad applications of shield in Chinese metro construction

Metro construction in China is confronted with the complicated geological conditions, which puts forward high requirements for the construction technology. Since the last century, China has been continuing the effort to introduce international advanced technologies of metro construction while considering the specific domestic conditions and geological conditions in China. Furthermore, in the practice of metro construction, three typical metro construction methods, namely the open cut method, covered-excavation method and shallow tunneling method are developed. Notably, the shield method, which is one of the shallow tunneling methods, has now become the most popular metro construction method in China.

The shield construction method is employed for the tunnel construction. The shield machine excavates underground, preventing sand soil and soft ground surface from collapse and maintaining the stability of excavation face via protection of the shield in excavation and lining operations (Editorial Department of Chinese Journal of Highway, 2015). Before shield construction is started, generally, the first step is to build a shaft and then to assemble the shield machine in this shaft. The soil excavated will be moved out of the ground by the shaft. The main process for the shield method includes boring, sediment transportation and segment assembly.

Studies and applications of shield method in China started from the city of Shanghai since the early 1960s. In 1991, Shanghai used the shield method for metro construction for the first time (Liu and $\mathrm{Du}, 1997$ ).
Compared with the traditional metro tunnel construction method, the shield method features less ground operation and higher degree of automation with small impact on the surrounding environment. Therefore, it is widely spread and very popular in Chinese metro construction (Hong, 2015). Nowadays, among those major cities possessing metro lines in the mainland of China, Shanghai basically builds almost all the metro lines in this way; more than $45 \%$ of metro lines in Beijing are also built by the shield method.

However, there are other methods used in metro construction, including:

(1) Open cut method: Open cut method refers to the way to dig up the ground from top to bottom to the designed elevation, and then to erect the main tunnel structures in the opposite way, and finally to finish the foundation pit backfill and restore the ground (Yang et al., 2010). Using this method, the production and living activities within the construction areas have to be hindered and a great impact is made on the social environment.

(2) Cover-excavation method: Cover-excavation method is developed, based on the open cut method, to carry on excavation, diaphragm wall and bored pile work and roof structure construction before the backfill restoration and ground transportation. This method is mainly used for construction of metro stations.

(3) Shallow tunneling method: Shallow tunneling method refers to performing all the tunnel excavation and construction of lining structures in the underground without digging the ground. Shallow tunneling method was first used in 1980s for the Jundu mountain railway double track tunnel and then this new technique was successful applied in Beijing metro lines, becoming a new popular tunnel construction method (He et al., 2009).

(4) Special construction methods: With the continuous advance of technologies, engineers often take advantages of the freezing method (Yang et al., 2003; Xu, 2004) and the chemical grouting method (Wu, 1990; Yao et al., 2006) for reinforcement of surrounding rock in some special urban areas where the tunnel goes through buildings in an underpinning way.

\subsection{Schedule control}

\subsubsection{Analysis of challenges}

Chinese metro construction is reaching an unprecedented scale (China Urban Rail Transit Association, 2016) despite the difficulties in accomplishing the metro projects and high operation cost. If the schedule of the metro projects was out of control, economic and social losses would be inevitable, resulting in great burden on the government. Compared with the developed countries, the development history of Chinese metro engineering is short, without enough experience in large-scale project management. 
Currently, most urban metro projects are constructed by shield method, which involves engineering, mechanical or electrical automation and other professional fields. Additionally, the project cycle is of long period with a tight schedule and both the personnel involved in one single project and the number of projects are increasing. Thus, it is challenging and demanding to coordinate the schedule, cost, quality and resource of project for the project management (Qian and He, 2004).

The project schedule management requires scientific methods to determine and prepare the construction schedule with resource supply plans and dynamically control the schedule according to the requirements on cost and quality so as to achieve project objectives (Ge, 2009). It is notable that excellent schedule management does not mean a schedule compression, which may lead to safety incidents (Webb et al., 2015). In light of the Chinese national conditions, the schedule management of a metro construction project mainly focuses on three aspects: Land acquisition and demolishing, project bidding and construction site management (Du, 2004; Gao, 2010).

(1) Land acquisition and demolishing: Since the metro lines run across various types of urban land and existing facilities, land acquisition and demolishing is a very important part of the preparatory work of a project and is also the key to accelerating the construction process. For the land acquisition and demolishing involving the interests of the state, certain groups and the individual, it is inevitable to be hindered by some vested interests ( $\mathrm{Yu}$, 2007). Currently, laws and regulations of land acquisition and demolition in China are lagging behind compared with some foreign countries. Local demolition policies are lack of consistency, which need to be standardized and unified. Furthermore, due to poor communications between local governments and the residents, improper means are likely to be used during this process, generating obstacles for the land demolition work and even the whole construction process.

(2) Project bidding: The project bidding is the phase when problems are most likely to arise. On the one hand, a metro construction project is a key public project with huge investments. In order to ensure a fair and transparent bidding process, the metro enterprises must establish rigorous and complex bidding procedures, which might extend the bidding period. On the other hand, the bidding process is complicated for a metro line involving quite a few tenders, which will certainly increase the workload of project bidding.

(3) Site schedule control: Construction is a production process of building entities, and site schedule control is the key section of the entire project construction process. The investment in metro engineering, construction entities, long construction period and complex construction technologies are all factors likely to cause delay on site.

\subsubsection{Measures and related research}

Countermeasures for the three challenges above and related research are:

(1) Measures for land requisition and demolishing: First of all, to accelerate the development of relevant laws and regulations on land acquisition and demolishing in China, opinions of each administrative department and local residents are solicited to establish a land requisition compensation standard according to laws and the local conditions (Du, 2015). Additionally, communications, policy interpretations and judicial means ahead of the demolition work are also employed to ensure that the construction will not be affected.

(2) Measures for project bidding: Through analysis of the bidding process, each procedure is necessary. As the bidding process cannot be changed, schedule control is taken only by compressing the working time of each procedure of the bidding process. Among all the procedures, calibration and contract negotiations are the two difficult steps to control, which, therefore, require special attention for process management so as to ensure the entire tender schedule ( $\mathrm{Du}, 2004)$.

(3) Measures for site schedule control: The key of construction site schedule control is to fulfill the overall time objective by preparing, verifying and dynamically controlling the schedule, ensuring that a project is delivered on schedule. For preparation of a schedule, it is necessary to clarify the scope and process of a project through the work breakdown structure (WBS). There are usually two ways to decompose a project, including the work flow decomposition and the work item decomposition. The construction site schedule control process can be divided into five stages: preparation, implementation, check, adjustment and examination (Yuan, 2015). Shenyang Metro, Dalian Metro, Guangzhou Metro and Shenzhen Metro efficiently control their construction periods by applying the construction site schedule control measures (Zhan and Liu, 2003; Li and Bao, 2007; Gao, 2010).

(4) Related research of schedule control: For schedule management theories, Wang et al. (2016) divided the main factors affecting the construction of metro station into three aspects including the external environment, the internal conditions and the construction process. Applying a new technology, Zhou et al. (2011) proposed a metro construction schedule management method based on linear graphs and a linear graphs based schedule management system was developed in 4D visualization, which could tackle the spatial conflicts in a construction schedule, realizing realtime and precise schedule control. Song (2013) expanded the applications of the critical chain method on metro project schedule control with analyses of the feasibilities, advantages and shortcomings, improving the critical chain 
method and generating a critical chain based metro project schedule management model.

\section{Examination on metro engineering related research of the National Natural Science Foundation of China}

Research programs on metro engineering funded by the NSFC cover six different departments among the eight departments of science and technology, including Department of Mathematics Science, Department of Earth Science, Department of Materials Science and Engineering, Department of Information Science, Department of Management Science, and Department of Chemical Science. Figure 3 shows the distribution of scientific issues of metro engineering research programs funded by the NSFC.

According to Fig. 3, 70\% of the programs funded by the NSFC are distributed in Department of Materials Science and Engineering, more specifically, focusing on such disciplines as structural engineering, geotechnical and foundation engineering, traffic engineering and disaster prevention engineering. In addition, quantities of research programs are engaged in the field of water conservancy science and ocean engineering. It is worth noting for the data of Department of Information Science that the interdisciplinary research signifies a growing trend from 2010 to apply information and automation based technologies into the field of metro engineering.

From 2012 to 2016, the NSFC funded a total of 91 programs with a total funding of approximately 52 million CNY, in which 49 general programs received total funding of 34 million CNY; 37 youth programs received the funding of 8 million CNY; one key program received the funding of almost 3 million CNY; one outstanding youth program received the funding of 4 million $\mathrm{CNY}$; one excellent youth program was funded by the science funding of 1 million and 300,000 CNY; and two regional programs received the funding of $810,000 \mathrm{CNY}$. The considerable volume of funds indicates the imminent demand to overcome the challenges of rapid development of metro engineering in China.

In the past five years, metro engineering research has blossomed and become a focus of many scientific research institutes, colleges and universities. The top eleven institutions that had government-funded programs (Fig. 4) were: (1) Huazhong University of Science and Technology, (2) Beijing Jiaotong University, (3) Beijing University of Technology, (4) Southwest Jiaotong University, (5) Tongji University, (6) Southeast University, (7) Chang'an University, (8) China Academy of Safety Science and Technology, (9) South China University of Technology, (10) Nanjing Tech University, and (11) Xi'an University of Architecture and Technology. According to the amount of funds, the top ten funded institutions (Fig. 5) were: (1) Beijing University of Technology, (2) Beijing Jiaotong University, (3) China Academy of Safety Science and Technology, (4) Huazhong University of Science and Technology, (5) Southwest Jiaotong University, (6) Southeast University, (7) Tongji University, (8) Nanjing Tech University, (9) Chang'an University, and (10) Tsinghua University.

In the light of Fig. 6, over the past five years from 2012 to 2016 , after a fluctuant rise from 2012, the number of funded research programs reached the top of 24 in 2014; while, the number of programs gradually declined during the next two years. On the other hand, the amount of funds,
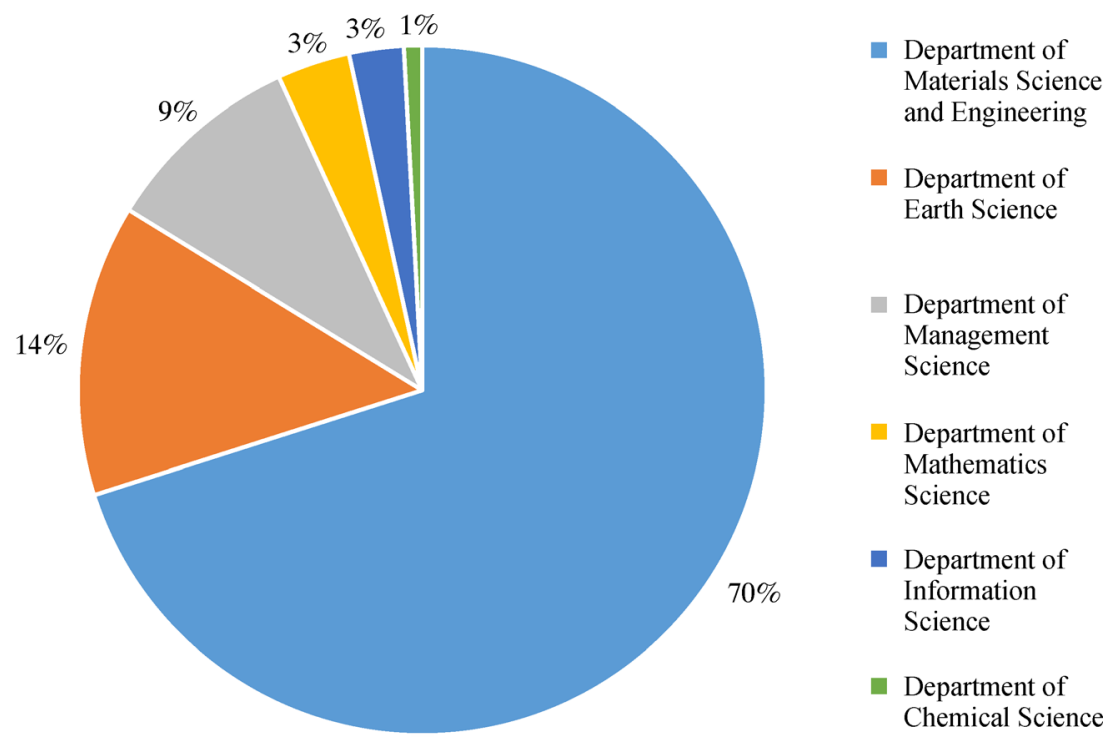

Fig. 3 The proportion and distribution of NSFC scientific programs of metro engineering (source: http://npd.nsfc.gov.cn/granttype1! index.action) 


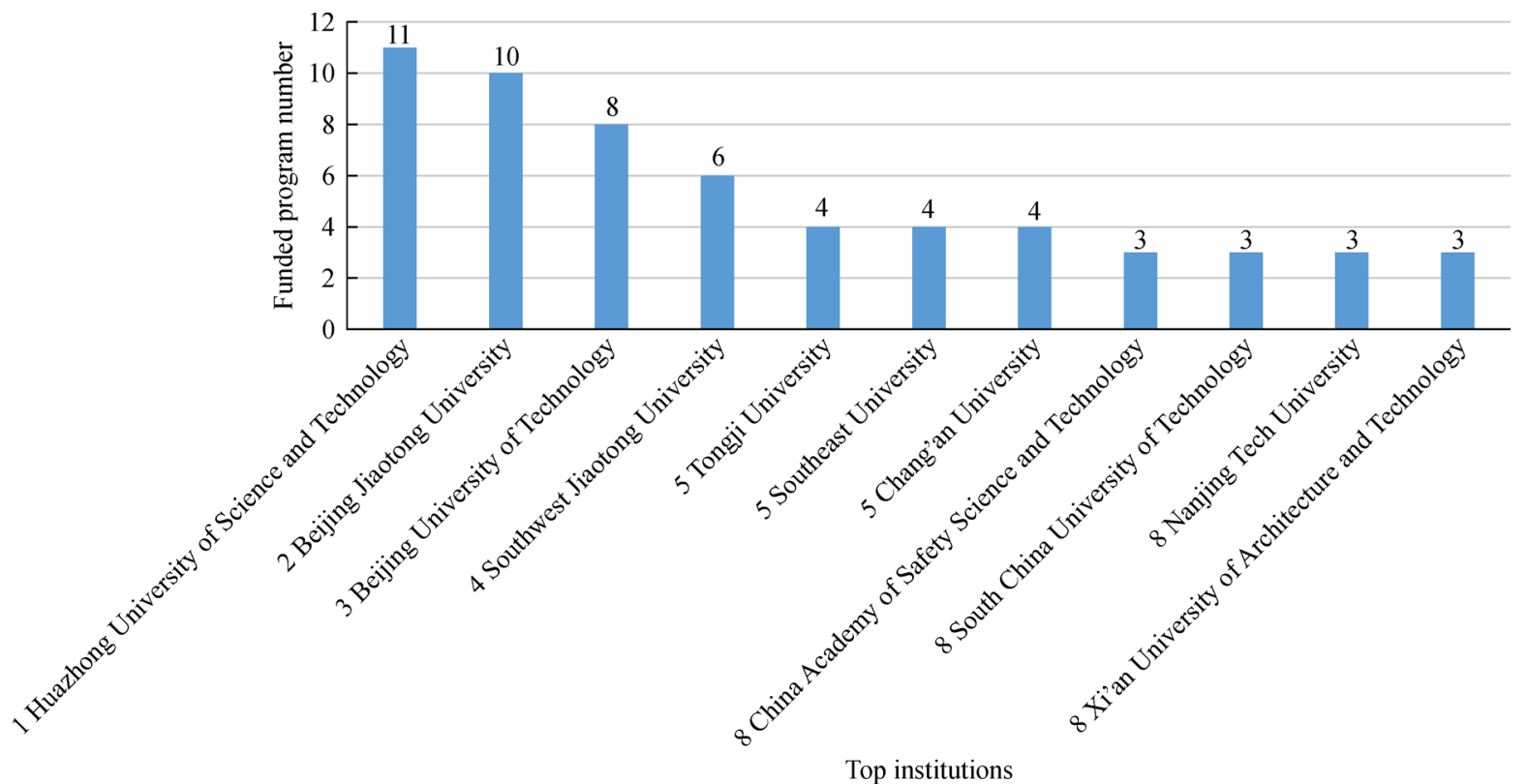

Fig. 4 Number of research programs of the top 11 funded institutions

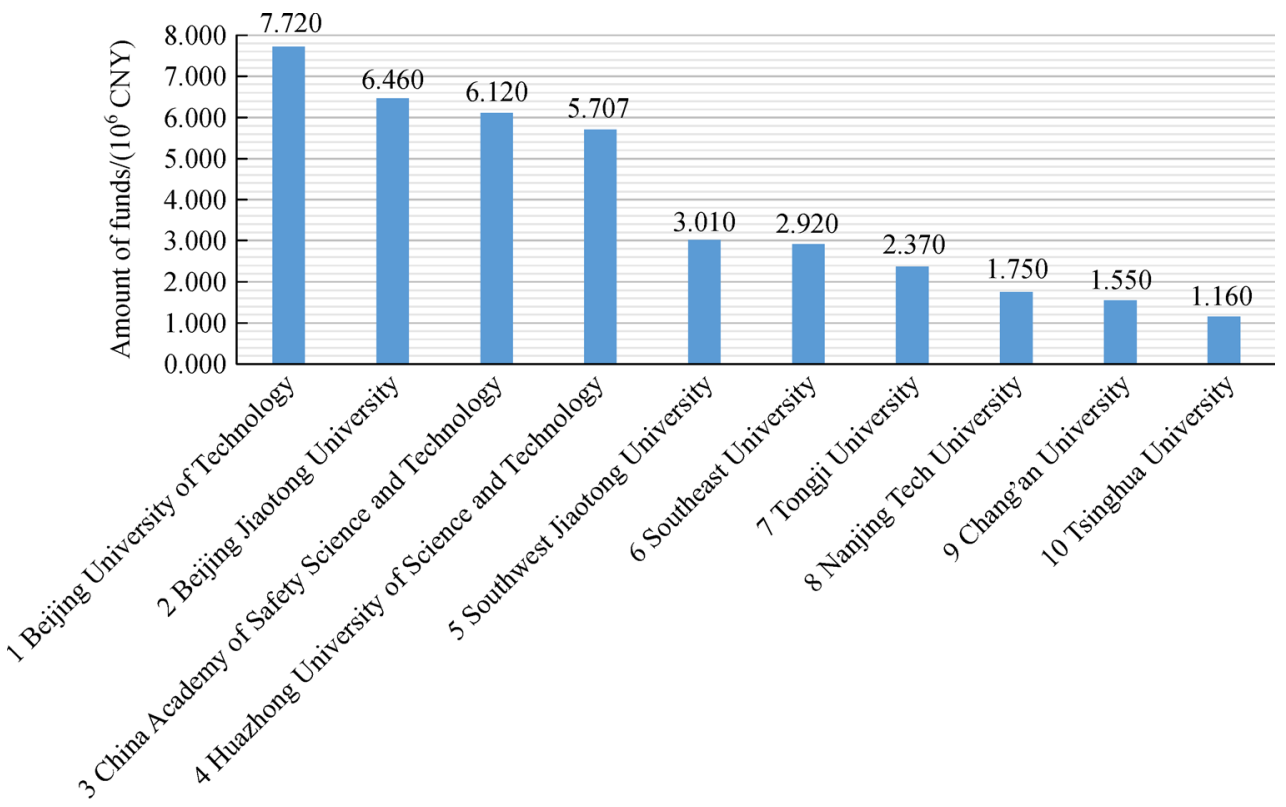

Top institutions

Fig. 5 Amount of funds of the top 10 funded institutions

as well as the number of programs changed in a similar way, indicating that the amount of funds given to an individual program remained almost the same.

\section{Conclusions}

This paper has reviewed the development of metro construction in China with a specific emphasis on its organization and market mode, cost structure, safety control and schedule management as well as recent research programs funded by the NSFC, coming to the following conclusions:

- With the domestic economic and social development, the pace of metro construction in China has been accelerating, the size of projects has been expanding and 


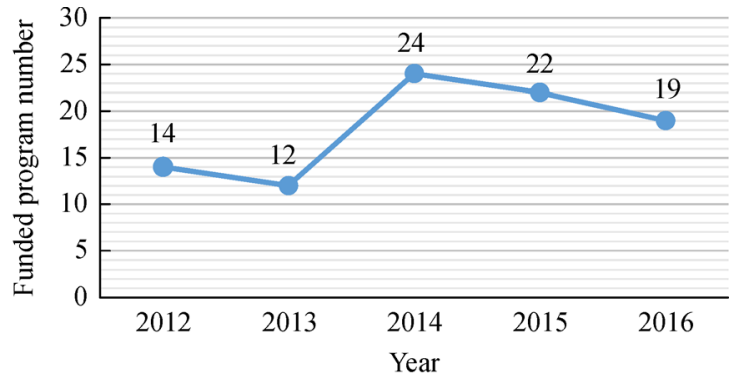

(a)

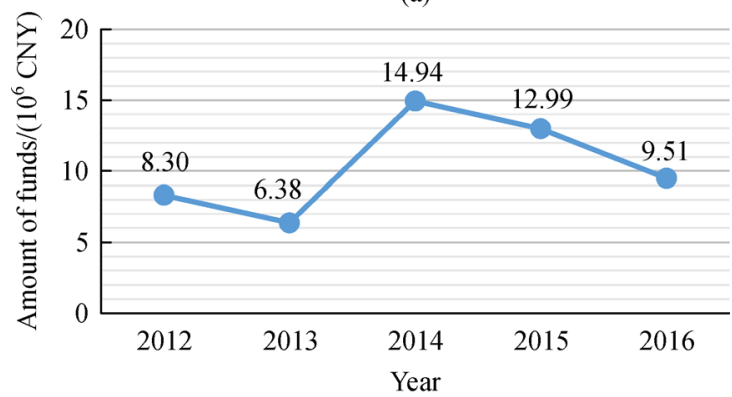

(b)

Fig. 6 Annual changes of (a) program number and (b) the amount of funds

a large number of technological innovations are made. China has become a world leader in metro construction and a source of innovation and new technologies.

- The organization and market mode of metro construction in China has a distinctive characteristic, with strong administrative intervention, while stepping towards a trend of marketization and diversification based on a PPP model for investment and financing; Factors like time, levels of economic and social development, vehicle type and special demands lead to cost differences between different metro lines and cities; The accident rate has been high due to falls from height, collapses and geological conditions, but the use of safety monitoring systems has helped significantly improve the safety performance; The focus of schedule management of shield metro construction mainly contains three aspects of land acquisition and demolishing, project bidding and construction site management, while the control of construction site schedule is the key to the whole project schedule management.

- The NSFC has consistently funded a number of innovative programs, while conventional research on structural, geotechnical, construction equipment and technology still accounts for the majority. Research on application of information and automation based technologies in the metro construction tends to attract more and more attention, becoming the future research focus in this specific field.

Acknowledgements The presented work has been supported by the National Natural Science Foundation General Program (Grant No. 51678265).

\section{Appendix}

Table A1 Statistics of metro construction plans of some domestic cities by 2015 (Source: http://www.sdpc.gov.cn/zcfb/zcfbtz/201501/ t20150116_660386.html)

\begin{tabular}{|c|c|c|c|c|c|c|c|c|c|}
\hline \multirow{2}{*}{ No. } & \multirow{2}{*}{ City } & \multirow{2}{*}{ Classification } & \multicolumn{2}{|c|}{ Population $/ 10^{6}$} & \multicolumn{2}{|c|}{ Economy $/\left(10^{9} \mathrm{CNY}\right)$} & \multicolumn{3}{|c|}{ Construction plan } \\
\hline & & & Urban Area & Total & GDP & Local taxation & Round & Period & Mileage $/ \mathrm{km}$ \\
\hline \multirow[t]{3}{*}{1} & Beijing & Municipality & 1600 & 2171 & 2297 & 472 & Early Stage & 1969-2003 & 114.10 \\
\hline & & & & & & & Round 1 & 2007-2016 & 536.40 \\
\hline & & & & & & & Round 2 & 2015-2021 & 262.90 \\
\hline \multirow[t]{2}{*}{2} & Shanghai & Municipality & 2415 & 2415 & 2497 & 552 & Round 1 & 2003-2010 & 567.00 \\
\hline & & & & & & & Round 2 & $2010-2015$ & 250.55 \\
\hline \multirow[t]{2}{*}{3} & Tianjin & Municipality & 900 & 1547 & 1654 & 267 & Round 1 & 2005-2015 & 205.10 \\
\hline & & & & & & & Round 2 & 2015-2020 & 228.10 \\
\hline \multirow[t]{2}{*}{4} & Chongqing & Municipality & 830 & 3017 & 1572 & 216 & Round 1 & 2006-2014 & 83.85 \\
\hline & & & & & & & Round 2 & $2012-2020$ & 215.04 \\
\hline \multirow[t]{2}{*}{5} & Guangzhou & Provincial capital & 1263 & 1350 & 1810 & 512 & Round 1 & 2003-2010 & 290.50 \\
\hline & & & & & & & Round 2 & 2012-2018 & 228.90 \\
\hline \multirow[t]{2}{*}{6} & Nanjing & Provincial capital & 642 & 824 & 972 & 102 & Round 1 & 2004-2015 & 119.00 \\
\hline & & & & & & & Round 2 & 2016-2021 & 196.40 \\
\hline \multirow[t]{2}{*}{7} & Hangzhou & Provincial capital & 640 & 902 & 1005 & 224 & Round 1 & 2005-2010 & 82.20 \\
\hline & & & & & & & Round 2 & 2013-2019 & 106.60 \\
\hline \multirow[t]{3}{*}{8} & Chengdu & Provincial capital & 712 & 1466 & 1080 & 117 & Round 1 & 2005-2015 & 108.00 \\
\hline & & & & & & & Round 2 & 2013-2020 & 262.40 \\
\hline & & & & & & & Round 3 & 2016-2020 & 124.40 \\
\hline
\end{tabular}


(Continued)

\begin{tabular}{|c|c|c|c|c|c|c|c|c|c|}
\hline \multirow{2}{*}{ No. } & \multirow{2}{*}{ City } & \multirow{2}{*}{ Classification } & \multicolumn{2}{|c|}{ Population $/ 10^{6}$} & \multicolumn{2}{|c|}{ Economy $/\left(10^{9} \mathrm{CNY}\right)$} & \multicolumn{3}{|c|}{ Construction plan } \\
\hline & & & Urban Area & Total & GDP & Local taxation & Round & Period & Mileage $/ \mathrm{km}$ \\
\hline \multirow[t]{3}{*}{9} & Wuhan & Provincial capital & 700 & 1061 & 1091 & 125 & Round 1 & 2004-2010 & 59.70 \\
\hline & & & & & & & Round 2 & 2010-2017 & 142.60 \\
\hline & & & & & & & Round 3 & 2015-2021 & 173.50 \\
\hline \multirow[t]{2}{*}{10} & Xi'an & Provincial capital & 600 & 871 & 581 & 65 & Round 1 & 2006-2016 & 92.90 \\
\hline & & & & & & & Round 2 & 2013-2021 & 65.10 \\
\hline \multirow[t]{2}{*}{11} & Shenyang & Provincial capital & 630 & 829 & 728 & 61 & Round 1 & 2003-2010 & 40.85 \\
\hline & & & & & & & Round 2 & 2012-2018 & 118.00 \\
\hline \multirow[t]{3}{*}{12} & Changchun & Provincial capital & 267 & 779 & 553 & 108 & Early Stage & $2000-2002$ & 14.00 \\
\hline & & & & & & & Round 1 & 2003-2010 & 37.50 \\
\hline & & & & & & & Round 2 & 2010-2019 & 67.70 \\
\hline \multirow[t]{2}{*}{13} & Urumqi & Provincial capital & 265 & 355 & 268 & 37 & Round 1 & 2012-2019 & 47.90 \\
\hline & & & & & & & Round 2 & 2016-2021 & 41.80 \\
\hline \multirow[t]{2}{*}{14} & Guiyang & Provincial capital & 300 & 462 & 289 & 37 & Round 1 & 2010-2020 & 56.00 \\
\hline & & & & & & & Round 2 & 2016-2022 & 114.10 \\
\hline \multirow[t]{2}{*}{15} & Wuxi & Prefecture-level city & 360 & 481 & 852 & 83 & Round 1 & 2008-2015 & 56.00 \\
\hline & & & & & & & Round 2 & 2013-2018 & 56.90 \\
\hline 16 & Wuhu & Prefecture-level city & 164 & 365 & 246 & 26 & Round 1 & 2016-2020 & 46.90 \\
\hline 17 & Luoyang & Prefecture-level city & 197 & 700 & 351 & 29 & Round 1 & 2008-2016 & 41.30 \\
\hline
\end{tabular}

\section{References}

Beijing Morning Post (2016). Beijing subway investment from 150 million $\mathrm{km}$ per kilometer cost rose to $\$ 1$ billion 100 million. http:// finance.chinanews.com/cj/2014/10-27/6719371.shtml, 2016-12-12 (in Chinese)

Chen H, Yuan D, Wang F (2015). Research on safety control technology of metro shield tunneling under high speed rail in weak stratum. China Civil Engineering Journal, (s1): 256-260 (in Chinese)

Chen J (2014). Introduction to Urban Rail Transit. Changsha: Central South University Press (in Chinese)

Chen L (2006). PPP financing mode in construction of urban rail transit systems. China Municipal Engineering, (3): 60-63, 94 (in Chinese)

Chen R (2005). Research on investment and financing mechanism of China's subway. Dissertation for the Master's Degree. Changsha: Central South University (in Chinese)

Chen W, Long Z, Li J (2013). Research on real time dynamic monitoring of subway construction. Journal of Underground Space and Engineering, 2: 344-351 (in Chinese)

China Urban Rail Transit Association (2016). Statistics and analysis of urban rail transit in 2015. Urban Rapid Rail Transit, 29(4): 6-11 (in Chinese)

Department of Transportation (2012). Introduction to Urban Rail Transit Management. Beijing: China Communications Press (in Chinese)

Ding L, Guo S (2015). Study on big data-based behavior modification in metro construction. Frontiers of Engineering Management, 2(2): $131-136$

Ding L, Zhou C (2012). Research on automatic identification and early warning of subway construction safety risk in complex environment. Chinese Engineering Science, 12: 85-93 (in Chinese)

Ding Z (2014). Study on influence of shield tunneling on adjacent buildings and deformation prediction. Dissertation for the Master's Degree. Hangzhou: Zhejiang University (in Chinese)

Ding Z, Liao Q, Shan X (2015). Large boulders formation of bored pile construction technology. Construction Technique, 44(23): 59-60 (in Chinese)

Du J (2004). Research on Shenzhen metro construction project management. Dissertation for the Master's Degree. Beijing: Tsinghua University (in Chinese)

Du Y (2015). Study on land expropriation and demolition in Guangzhou Metro Construction. Dissertation for the Master's Degree. Kunming: Yunnan University of Finance and Economics (in Chinese)

Editorial Department of Chinese Journal of Highway (2015). A summary of the academic research on Chinese tunnel engineering 2015. Chinese Journal of Highway, 28(5): 1-65 (in Chinese)

Gao Y (2010). Research on the project management of Dalian Metro. Dissertation for the Master's Degree. Changchun: Jilin University (in Chinese)

Ge L (2009). Some views on schedule management in engineering construction. Shanxi Architecture, 35(30): 201-202 (in Chinese)

Gu M (2011). Present situation and prospect of urban rail transit in China. China Railway, 10: 53-54 (in Chinese)

Guo S, Luo H, Kong L (2015). Content based safety training for subway construction workers. Journal of Civil Engineering and Management, 32(4): 53-58 (in Chinese)

He C, Jiang Z, Liu C (2009). Construction technology of shallow buried tunnel. Municipal Technology, 27(3): 274-279 (in Chinese) 
He F (2004). On BOT and BT project investment. Tunnel Construction, 24(4): 68-69 (in Chinese)

Hong K (2015). Development and prospect of tunnel and underground engineering in China. Tunnel Construction, 2: 95-107 (in Chinese)

Huang D, Zhou Y, Dai S (2010). Construction technology of shield tunneling through historic buildings in Shanghai the Bund tunnel. Construction Technique, 9: 43-46 (in Chinese)

Jin H, Liu Y, Zhong Q (2008). Current situation and prospect of urban rail transit safety risk management in China. China Survey, 2: 216220 (in Chinese)

Jin H, Zhang J, Wu F, Ren G (2014). Theory and Practice of Urban Rail Transit Engineering Monitoring. Beijing: China Building Industry Press (in Chinese)

Li H, Bao L (2007). Shenyang metro project schedule control. Modern Urban Rail Transit, 3: 50-51 (in Chinese)

Li L (2014). Study on the method of judging the safety degree of super large diameter shield passing through high risk pipeline and its measurement. Modern Tunnel Technology, 51(5): 134-138 (in Chinese)

Li Q, Guo J, Liu C (2014). Construction risk management of Shenzhen Metro Line 5. Railway Engineering, 5: 47-49 (in Chinese)

Li X (2011). Research on safety risk early warning index system of subway construction. Dissertation for the Master's Degree. Wuhan: Huazhong University of Science and Technology (in Chinese)

Liu G, Du W (1997). Development and prospect of underground engineering construction technology in China. Building Technology, 7: 480-483 (in Chinese)

Liu K D (2011). Research and Application of Security System for Urban Rail Transit System. Beijing: China Architecture \& Building Press (in Chinese)

Liu L (2015). Study on financing mode of city subway construction-Taking Nanchang subway as a case. Dissertation for the Doctoral Degree. Nanchang: Nanchang University (in Chinese)

Ministry of Commerce of the People's Republic of China (2015). Rail transit industry investment promotion report. http://www.fdi.gov.cn/ 1800000121_35_398_0_7.html, 2017-3-1 (in Chinese)

Ministry of Housing and Urban Rural Development of People's Republic of China (2017). Accident Letters. http://sgxxxt.mohurd. gov.cn/Public/AccidentList.aspx, 2017-2-8 (in Chinese)

Qian Q, He Z (2004). The development of rail transit and the application of high and new technology. Railway Construction Technology, 1: 15 (in Chinese)

Ren J, Li Q, Zheng Z (2014). Study on deformation law of ground surface and adjacent buildings induced by shield. Journal of Railway Engineering Society, (1): 69-74 (in Chinese)

Song J (2013). Research on schedule management of rail transit construction project based on critical chain technology. Dissertation for the Master's Degree. Zhengzhou: Henan University of Technology (in Chinese)

Song J, Chen G (2015). Research on the main problems and countermeasures of investment and financing mode of China's subway projects. Building Economy, 36(11): 29-32 (in Chinese)

Song X (2001). The sustainable development of Shanghai rail transit. Urban Mass Transit, 4(4): 47-50 (in Chinese)

Sun Y (2014). Exploration on engineering management practice of China's high speed railways. Frontiers of Engineering Management,
1(3): $232-240$

Sun Y, Guan F (2012). Influence of shield tunneling on settlement of masonry structure buildings. China Railway Science, 33(4): 38-44 (in Chinese)

Sureeyatanapas P, Yang J B, Bamford D (2014). Evaluation of corporate sustainability. Frontiers of Engineering Management, 1(2): 176194

Tao L, Li J, Wang G (2013). The application of CRD + top support control technology in the project of closedown. Journal of Railway Engineering Society, 30(7): 74-79 (in Chinese)

Wang H, Cui $T$ (2013). Analysis on influence of shield tunnel construction on underground pipeline. Journal of Underground Space and Engineering, 9(2): 365-370 (in Chinese)

Wang L (2016). Technical and Economic Indexes of Urban Rail Transit Project. Beijing: China Architecture \& Building Press (in Chinese)

Wang M (2003). China is the world's largest and most complex tunnel and underground engineering, the fastest growing country in the future. Railway Standard Design, 1: 1-4 (in Chinese)

Wang Q (2005). Study on the application of PPP model in infrastructure construction in China. Dissertation for the Master's Degree. Wuhan: Wuhan University of Technology (in Chinese)

Wang M (2014). Present situation, existing problems and development ideas of shield tunneling machine in China. Tunnel Construction, 34 (3): 179-187 (in Chinese)

Wang T, Xu L, Zhao N (2016). Study on the influencing factors and the ways of the construction of subway station. Journal of Railway Engineering Society, 5: 89-92, 115 (in Chinese)

Wang W (2012a). Protection scheme of shield tunnel under the West to East Gas Pipeline. Journal of Railway Engineering Society, 29(10): 70-74 (in Chinese)

Wang X (2012b). Construction technology of special geological loess tunnel. Journal of Railway Engineering Society, 29(3): 96-100 (in Chinese)

Wang Y, Chen W, Zhang W (2013). Research on the construction of hierarchical monitoring index system for urban rail transit engineering. Journal of Civil Engineering and Management, 3: 97-102 (in Chinese)

Wang Z, Wang M (2002). Influence of shield construction on surrounding buildings and its treatment measures. Chinese Journal of Safety Science, 2: 48-52 (in Chinese)

Webb C, Gao L, Song L (2015). Schedule compression impact on construction project safety. Frontiers of Engineering Management, 2 (4): $344-350$

Wei G, Hong J, Wei X (2012). Analysis of additional load on adjacent underground pipelines caused by double circular shield construction. Rock Soil Mechanics, 33(6): 783-790 (in Chinese)

Wu X, Chen Y, Zhang L (2013). Study on safety monitoring and early warning management and evaluation criteria for metro construction. Journal of Railway Engineering Society, 5: 107-111 (in Chinese)

Wu T (1990). Grouting reinforcement technology. Exploration Engineering, 2: 49-55 (in Chinese)

Xia Y (2000). Innovation of financing mode of metro line two project. Shanghai Urban Management, 5: 14-15 (in Chinese)

Xiao M, Guo S, Yu Q (2015). Effect analysis of subway construction safety training based on graphic language. Journal of Civil Engineering and Management, 1: 59-64 (in Chinese) 
$\mathrm{Xu} \mathrm{J}$ (2004). The application of freezing method in the construction of Shanghai subway connection passage. China Municipal Engineering, (5): 63-65 (in Chinese)

Xu S, Luo H (2014). Worker behavior safety training system based on graphic language. Journal of Civil Engineering and Management, 3: 51-55, 77 (in Chinese)

Xu Z, Han Q, Zheng G (2013). Measurement and analysis of the influence of metro tunnel on historic buildings. Journal of Geotechnical Engineering, 2: 364-374 (in Chinese)

Yan X, Ye Y, Zhang M (2012). Analysis on the influence of subway tunnel under existing railway bridge construction. Railway Engineering, 6: 84-85 (in Chinese)

Yang K (2009). Study on the protection of ancient buildings in Xi'an subway construction. Dissertation for the Master's Degree. Beijing: China University of Geosciences (in Chinese)

Yang P, Yu C, Dong C (2003). Application of artificial freezing method in Nanjing subway station. Rock Soil Mechanics, S2: 388-391 (in Chinese)

Yang W (2014). Study of sustainable urban rail transit development model in China. Frontiers of Engineering Management, 1(2): 195201

Yang X, Liu D, Zhang F (2010). Study on the stability of foundation pit support in open excavation method of subway tunnel. Journal of Underground Space and Engineering, 6(3): 516-520 (in Chinese)

Yang X, Wen K (2010). Construction technology of shield tunnel crossing historical relics. In: Key Technology Forum of Urban Rail Transit. Shanghai (in Chinese)

Yao Y, Yang J, Wang Z (2013). The influence of foundation pit excavation on the deformation of tunnel and pipeline is analyzed. Journal of Underground Space and Engineering, 9(S2): 2029-2033 (in Chinese)

Yao Z, Wang H, Wang J (2006). New development of grouting reinforcement technology. Mining Engineering in China, 35(4): 3134 (in Chinese)

You L, Wang X, Gong Y (2012). Study on the foundation treatment technology of shield tunnel under new railway station. Journal of Railway Engineering Society, 6: 104-108 (in Chinese)

Yu J (2007). Reflections on the problems of land acquisition and demolition. Zhejiang Land and Resources, 11: 22-24 (in Chinese)

Yuan J (2015). Analysis on the schedule management of metro engineering. Shanxi Architecture, 14: 245-246 (in Chinese)

Zhai J (2009). Construction technology of expansive soil tunnel. Railway Construction Technology, (1): 149-151 (in Chinese)

Zhan X, Liu H (2003). Project management and schedule control of
Guangzhou Metro Line 2. Research on Urban Rail Transit, 6(6): 9497 (in Chinese)

Zhang J (2014a). Risk assessment method of metro shield tunnel based on Bayesian network. Research on Urban Rail Transit, 3: 30-34 (in Chinese)

Zhang M, Liu X, Du Y (2013). Analysis of the influence of shield tunneling on adjacent buildings. Journal of Beijing University of Technology, 39(2): 214-219 (in Chinese)

Zhang Y (2014b). Research on PPP project management mode of Nanjing metro. Reform \& Openning, 19: 90-92 (in Chinese)

Zhang Y, Wang J, Lv S (2006). Research on the financing model of the 2 phase of Shenzhen metro line four. Construction Economics, 9: 1922 (in Chinese)

Zhang Y, Hui G, Su Y (2008). Construction technology of a special stratum of rock and sand and gravel in a shield section of Beijing Metro Line 4. Modern Tunnel Technology, (S1): 447-451 (in Chinese)

Zhang Y (2009). Study on the management system and mechanism of Chinese metro. China Bidding, 5: 20-23 (in Chinese)

Zhang Z, Zhang M (2013). Deformation prediction and construction control of earth pressure balance shield tunnel crossing tunnel in soft soil. Chinese Journal of Rock Mechanics and Engineering, (S2): 3428-3439 (in Chinese)

Zhao Q (2013). Construction technology of shield tunneling through ancient buildings. Urban Construction Theory, 12 (in Chinese)

Zhou S, Rong J, Chen L (2013). A single large diameter double subway shield tunnel construction and monitoring. Journal of Underground Space and Engineering, 9(2): 365-372 (in Chinese)

Zhou W (2006). Study on the influence of Wuhan Yangtze River Tunnel Construction on surrounding historic buildings. Dissertation for the Master's Degree. Wuhan: Huazhong University of Science and Technology (in Chinese)

Zhou Y, Zhou C, Wang N (2011). Research and application of 4D schedule control system for subway project based on linear graph. China Civil Engineering Journal, (S1): 209-214 (in Chinese)

Zhu G (2014). China's engineering education: Situation \& Outlook. Frontiers of Engineering Management, 1(1): 105-112

Zhu H, Ding W, Qiao Y (2014a). The control system and its application of shield tunnel. Journal of Geotechnical Engineering, 11: 19831993 (in Chinese)

Zhu H, Ding W, Qiao Y, Xie D (2014b). Micro-disturbed construction control technology system for shield driven tunnels and its application. Chinese Journal of Geotechnical Engineering, 36(11): 1983-1993 (in Chinese) 